\title{
The impact of COVID-19 on gastric cancer surgery: a single-center retrospective study
}

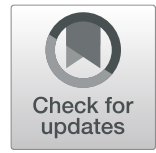

Yu-xuan $\mathrm{Li}^{1 \dagger}$, Chang-zheng He ${ }^{1 \dagger}$, Yi-chen $\mathrm{Liu}^{1 \dagger}$, Peng-yue Zhao ${ }^{1}$, Xiao-lei Xu' , Yu-feng Wang ${ }^{2}$, Shao-you Xia ${ }^{1{ }^{*}}$ and Xiao-hui Du ${ }^{1 *}$ (D)

\begin{abstract}
Background: The coronavirus disease 2019 (COVID-19) has been declared a global pandemic by the World Health Organization. Patients with cancer are more likely to incur poor clinical outcomes. Due to the prevailing pandemic, we propose some surgical strategies for gastric cancer patients.

Methods: The 'COVID-19' period was defined as occurring between 2020 and 01-20 and 2020-03-20. The enrolled patients were divided into two groups, pre-COVID-19 group (PCG) and COVID-19 group (CG). A total of 109 patients with gastric cancer were enrolled in this study.

Results: The waiting time before admission increased by 4 days in the CG (PCG: 4.5 [IQR: 2, 7.8] vs. CG: 8.0 [IQR: 2, 20]; $p=0.006$ ). More patients had performed chest $C T$ scans besides abdominal $C T$ before admission during the COVID-19 period (PCG: 22 [32\%] vs. CG: 30 [73\%], $p=0.001$ ). After admission during the COVID period, the waiting time before surgery was longer (PCG: 3[IQR: 2,5] vs. CG: 7[IQR: 5,9]; $p<0.001$ ), more laparoscopic surgeries were performed (PCG: 51[75\%] vs. CG: 38[92\%], $p=0.021$ ), and hospital stay period after surgery was longer (7[IQR: 6,8] vs.9[IQR:7,11]; $p<0.001$ ). In addition, the total cost of hospitalization increased during this period, (PCG: 9.22[IQR: $7.82,10.97]$ vs. CG: $10.42[$ IQR:8.99,12.57]; $p=0.006$ ).
\end{abstract}

Conclusion: This study provides an opportunity for our surgical colleagues to reflect on their own services and any contingency plans they may have to tackle the COVID-19 crisis.

Keywords: Gastric cancer, Coronavirus disease 2019, COVID-19, Retrospective analysis

\section{Background}

A respiratory epidemic defined as 'coronavirus disease 2019 (COVID-19)' emerged in Wuhan city, Hubei Province, China. Forty-one patients were admitted to hospitals with an initial pneumonia diagnosis of an unknown etiology. Most of these patients had visited a local fish and wild animal market in November [1,2]. Since then, COVID-19 has been declared a global pandemic by the World Health Organization (WHO). According to the

\footnotetext{
* Correspondence: xiasyue@163.com; duxiaohui301@sina.com

${ }^{\dagger}$ Yu-xuan Li, Chang-zheng He and Yi-chen Liu contributed equally to this work.

'Department of General Surgery, Chinese PLA General Hospital, Beijing 100853, PR China

Full list of author information is available at the end of the article
}

situation report-77 of WHO (Data as of 6th April, 2020), more than 1.2 million people had been infected across the globe [3].

Most patients presented with fever, dry cough and dyspnea. However, incidences of isolated or coexisting abdominal and gastrointestinal symptoms such as diarrhea, nausea, vomiting and abdominal discomfort were also common [4]. Due to the route of transmission of this disease, stringent precautionary measures for patients and particularly hospital staffs who were at great risk were implemented $[5,6]$. Through droplet and contact transmission, the virus can be spread by asymptomatic patients. The safety of nurses, surgeons, patients and their families is of paramount importance $[7,8]$.

\section{$\triangle B M C$}

(c) The Author(s). 2020 Open Access This article is licensed under a Creative Commons Attribution 4.0 International License, which permits use, sharing, adaptation, distribution and reproduction in any medium or format, as long as you give appropriate credit to the original author(s) and the source, provide a link to the Creative Commons licence, and indicate if changes were made. The images or other third party material in this article are included in the article's Creative Commons licence, unless indicated otherwise in a credit line to the material. If material is not included in the article's Creative Commons licence and your intended use is not permitted by statutory regulation or exceeds the permitted use, you will need to obtain permission directly from the copyright holder. To view a copy of this licence, visit http://creativecommons.org/licenses/by/4.0/. The Creative Commons Public Domain Dedication waiver (http://creativecommons.org/publicdomain/zero/1.0/) applies to the data made available in this article, unless otherwise stated in a credit line to the data. 
Gastric cancer surgery is not a front-line subject in the fight against COVID-19, however, in such a special situation, due to disease consumption, malnutrition, coupled with chemotherapy, gastric cancer patients may be immunocompromised, which leads to more susceptible to COVID-19 and poor clinical outcomes $[9,10]$. Based on our experiences during the pandemic period, we propose some surgical strategies for gastric cancer patients.

\section{Methods}

\section{Study design and patients}

The General Surgery Department of our hospital serves as a final referral unit for a cluster of hospitals from other districts and provides specialized services for gastric cancer. On January 20th, 2020, the National Health Commission announced that the prevention and control measures for the COVID-19 infectious would be category A management. As a result, intensified clinical management strategies for outpatients, inpatients and discharged COVID-19 cases were intensified. On March 20th 2020, and the consecutive days, there were no new locally confirmed COVID-19 cases in Beijing. This was a milestone in the battle against this virus. Based on the above factor, we defined the 'COVID-19' period as occurring between 2020 and 01-20 and 2020-03-20. Data obtained during this period was compared with a similar preceding 1-month period between 2020 and 12-20 and 2020-1-19 which we termed the 'Pre-COVID-19' period. Determined by which period the enrolled patients were admitted to the hospital, they were divided into two groups; the pre-COVID-19 group (PCG) and the COVID-19 group (CG).

We aimed to compare the differences in demographics, baseline characteristics, clinicopathological features, and health economics between the two groups to investigate the feasibility of gastric surgery during the pandemic of COVID-19.

This study was approved by the Institutional Review Board of the General Hospital of PLA. Inclusion criteria were: i. Patients diagnosed with gastric cancer by pathological examinations and whose electronic medical records were available; ii. Patients who received surgical treatment. On the contrary, patients who received neoadjuvant chemotherapy (NACT) or had emergency surgical procedures were excluded. A total of 109 patients with gastric cancer were enrolled in this study. They were diagnosed according to The NCCN Clinical Practice Guidelines in Oncology (NCCN Guidelines) for Gastric Cancer. Operations were performed by the same team of surgeons.

\section{Data collection}

The medical records of patients were obtained and analyzed by our research team. The clinical, epidemiological, radiological, laboratory characteristics from electronic medical records were summarized. These data included patient demographics and baseline characteristics (sex, age, body mass index, comorbidity, clinical TNM classification, pathological TNM classification, hemoglobin, CEA, CA199, AFP, CA724), origin of patients (from local district or other provinces), operative method (open surgery or laparoscopic surgery), operating time, estimated blood loss, postoperative complications, postoperative fever, waiting time before admission, length of postoperative hospital stay, hospital costs etc. We defined the waiting time before admission as the period from the time when the patient came to our outpatient clinic to hospitalization. Length of postoperative hospital stay was defined as the period from the time when patient had undergone surgery to discharge.

\section{Statistical analysis}

The SPSS version 26.0 was used for statistical analysis. The assumption of data normality for all quantitative variables data was verified with the Shapiro-Wilk test. For the normally distributed variables, data were expressed as mean \pm standard deviation( $\pm s$ ). The median and interquartile ranges were used to express measurement data that did not conform to normal distribution. Count data were expressed by frequency and percentage (\%). The students $t$ test was used to compare the means for normally distributed variables while the Mann-Whitney $U$ test was used for variables without normal distribution. Statistical analysis of count data was done using chi-square test or Fisher exact probability method. The $p$-value less than 0.05 was considered significant.

\section{Results \\ Study population and baseline demographics}

Between December 20th, 2019 and March 20th, 2020, a total of 109 patients were enrolled. In this study, 68 were enrolled into PCG while 41 were enrolled into CG (Fig. 1). Patient demographics for PCG and CG were shown in Table 1 . There was no statistically significant difference in age, sex and body mass index between the two groups $(p>0.05)$.

\section{Clinicopathological data of all patients enrolled before or after 20th January}

Pre-COVID-19, admissions to the gastric unit totaled 68 cases over the 1-month period. During COVID-19, this total dropped by $30 \%$ to 41 admissions. In contrast, the waiting time before admission increased by 4 days (PCG: 4.5 [IQR: 2, 7.8] vs. CG:8.0 [IQR: 2,20]; $p=0.006$ ). The proportion of local patients in PCG was lower when compared to those in CG (3 [4\%] vs. 16 [39\%]; $p<$ 0.001). More patients had performed chest CT scan besides abdominal CT before admission during the 


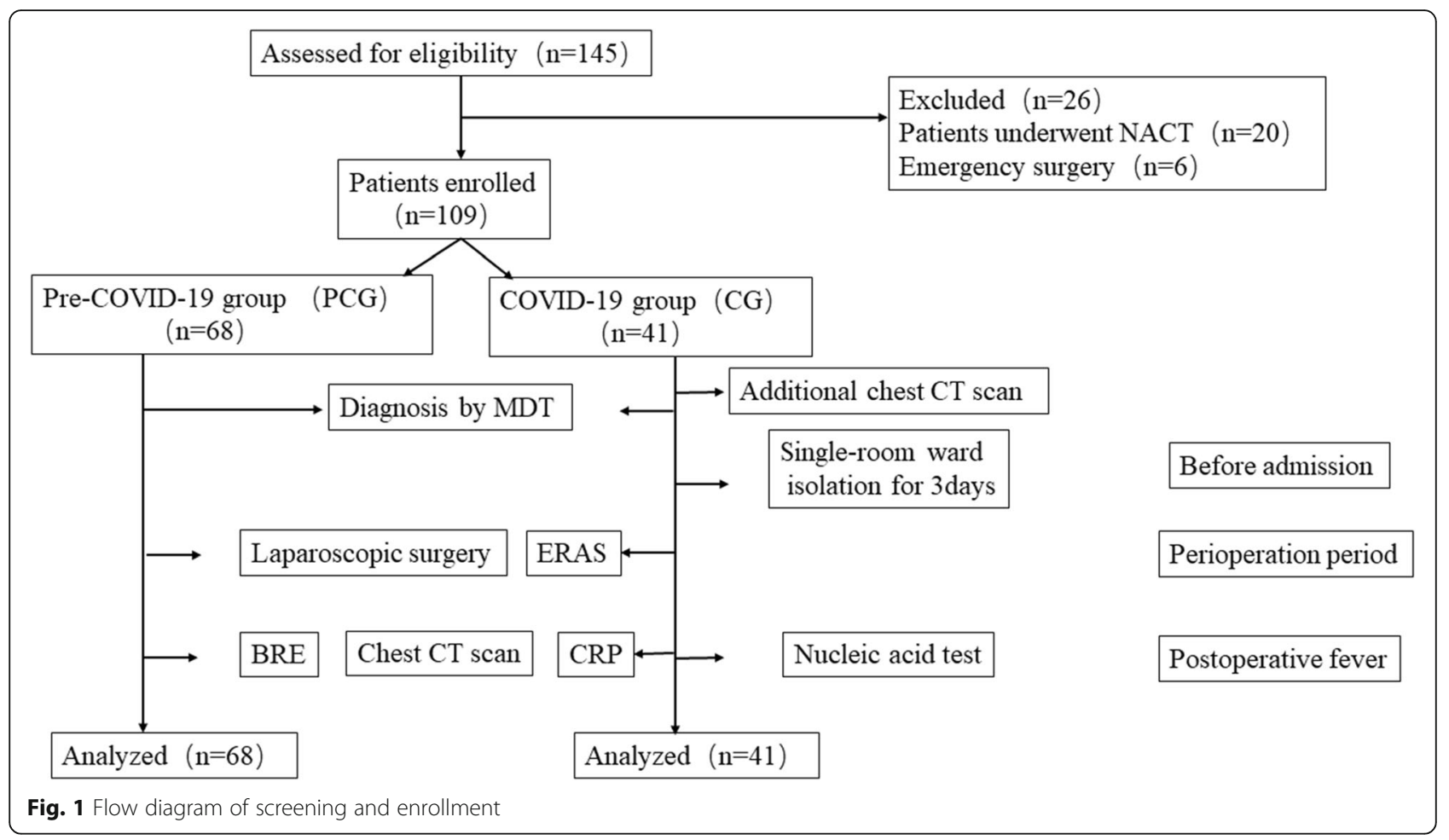

COVID-19 period (PCG:22[32\%] vs. CG:30[73\%], $p=$ $0.001)$. These results were shown in Table 2.

During the COVID-19 period, the waiting time before surgery was longer (PCG: 3[IQR: 2,5] vs. CG: 7[IQR: 5,9]; $p<0.001)$ with more laparoscopic surgeries being performed (PCG: $51[75 \%]$ vs. CG: $38[92 \%], p=0.021$ ). In addition, the length of hospital stay after surgery was longer (7[IQR: 6,8] vs.9[IQR:7,11]; $\mathrm{p}<0.001$ ). There were no significant statistical differences in surgical time, pathological diagnosis, TNM staging, and in complications associated with pneumonia, blood transfusion, the highest temperature and screening test between the two groups $(p>0.05)$. These results were shown in Tables 3 and 4 .

Table 1 Baseline demographical data of all patients enrolled

\begin{tabular}{llll}
\hline Demographics & PCG $(\boldsymbol{N}=\mathbf{6 8})$ & $\mathbf{C G}(\boldsymbol{N}=\mathbf{4 1})$ & $\boldsymbol{P}$ \\
& $\mathbf{M} \pm \mathbf{S D}$ or $\mathbf{N}(\%)$ & $\mathbf{M} \pm \mathbf{S D}$ or $\mathbf{N}(\%)$ & \\
\hline Age (years) & $59.60 \pm 11.04$ & $58.41 \pm 10.27$ & 0.578 \\
Sex & & & 0.583 \\
$\quad$ & & & \\
$\quad$ Male & 45 & 16 & 0.099 \\
BMl & 23 & $23.30 \pm 2.91$ & $0.000^{*}$ \\
Origin of patients & $24.37 \pm 3.68$ & & \\
$\quad$ Local patients & 3 & 16 & \\
$\quad$ Other provinces & 65 & 25 & \\
\hline
\end{tabular}

PCG Pre-COVID-19 group, CG COVID-19 group, M Mean, SD Standard deviation, $N$ Number

${ }^{*} P<0.05$, statistically different
Health economics data of all patients enrolled before or after 20th January

The total cost of hospitalization increased during the COVID-19 period, (PCG: 9.22[IQR:7.82,10.97] vs. CG: 10.42[IQR:8.99,12.57]; $p=0.006$ ), The cost of medicines, treatment and other aspects such as beds, diets etc. were higher in CG $(\mathrm{p}>0.05)$. These results were shown in Table 5.

\section{Discussion}

In this study, the $30 \%$ fall in case load during the COVID-19 period and the proportion of local patients in PCG being lower than those in CG could be attributed to the travel restrictions and lockdown imposed on Beijing. During the COVID-19 period, the use of telemedicine and remote counselling has made great strides. This has helped in reducing the number of outpatients and unnecessary physical contacts. Tolone et al. used triage questionnaires for elective surgical patients in cases of positive symptoms and contact history associated with COVID-19. These questionnaires were administered through the telephone [11]. Gambardella et al. reported their experience regarding treatment for old cancer patients. They documented several procedures that could help in preventing disease transmission among patients. These procedures encompassed the use of a telephone triage before admission, and the application of telemedicine [12]. In CG, appointments and triage protocols were to be performed virtually through telemedicine 
Table 2 Preoperative clinicopathological data of all patients enrolled

\begin{tabular}{|c|c|c|c|}
\hline Clinicopathologic data & $\begin{array}{l}\text { PCG }(N=68) \\
M(I Q R) \text { orN (\%) }\end{array}$ & $\begin{array}{l}\text { CG }(N=41) \\
M(I Q R) \text { orN (\%) }\end{array}$ & $P$ \\
\hline Admission waiting (day) & $4.5(2-7.75)$ & $8.0(2-20)$ & $0.006^{*}$ \\
\hline Operation waiting (day) & $3(2-5)$ & $7(5-9)$ & $0.000^{*}$ \\
\hline Comorbidity & & & 0.144 \\
\hline Yes & 46 & 22 & \\
\hline No & 22 & 19 & \\
\hline Tumor marker & & & 0.298 \\
\hline CEA & 2.12 & 1.85 & 0.771 \\
\hline AFP & 2.85 & 3.01 & 0.883 \\
\hline CA199 & 9.70 & 9.63 & 0.863 \\
\hline CA724 & 2.03 & 2.13 & \\
\hline Clinical TNM stage & & & 0.112 \\
\hline I & 17 & 4 & \\
\hline$\|$ & 18 & 14 & \\
\hline III & 30 & 23 & \\
\hline IV & 3 & 0 & \\
\hline Hemoglobin & $138.50(119.25-148.75)$ & $143.00(119.50-151.00)$ & 0.726 \\
\hline Chest CT scan & & & $0.000^{*}$ \\
\hline Yes & 24 & 30 & \\
\hline No & 44 & 11 & \\
\hline
\end{tabular}

PCG Pre-COVID-19 group, CG COVID-19 group, CT Computed tomography; C, $N$ Number

${ }^{*} P<0.05$, statistically different

such as mobile phones, applications or the websites, thereby, clinical visits were to be performed based on reserved numbers and recommended time.

The COVID-19 outbreak brought to the importance of infection control measures for pandemic diseases.

Table 3 Intraoperative clinicopathological data of all patients enrolled

\begin{tabular}{|c|c|c|c|}
\hline Clinicopathologic data & $\begin{array}{l}\text { PCG }(N=68) \\
M \pm \text { SD or } N(\%)\end{array}$ & $\begin{array}{l}C G(N=41) \\
M \pm S D \text { or } N(\%)\end{array}$ & $P$ \\
\hline Surgery time (min) & $184.74 \pm 44.36$ & $195.00 \pm 57.49$ & 0.298 \\
\hline Estimated blood loss (ml) & $100(50-137)$ & $100(50-150)$ & 0.569 \\
\hline Operative method & & & $0.021^{*}$ \\
\hline Open & 17 & 3 & \\
\hline Laparoscopic & 51 & 38 & \\
\hline Combine organ resection & & & $0.000^{*}$ \\
\hline Yes & 1 & 0 & \\
\hline No & 67 & 41 & \\
\hline Transfusion of blood & & & 0.172 \\
\hline Yes & 4 & 6 & \\
\hline No & 64 & 35 & \\
\hline
\end{tabular}

PCG Pre-COVID-19 group, CG COVID-19 group, M Mean, SD Standard deviation, $N$ Number. ${ }^{\mathrm{a}} M$ Median, $I Q R$ Inter-quartile range

${ }^{*} P<0.05$, statistically different
Successful implementation of infection control measures require the strict management of inpatients during this period. Patients with cancers have been established to be immunocompromised, which makes them more susceptible to COVID-19 $[4,10]$. Therefore, we suggest that all outpatients should be triaged before admission to reduce the possibility of exposure in hospital. In CG, to screen for suspected infections, patients were subjected to chest CT scans and new coronavirus nucleic acid tests before admission, which explains the longer waiting time before admission in CG. In addition, the provinces were relatively isolated during the pandemic, therefore, compared with PCG, the proportion of local patients in CG had increased.

After admission, patients were isolated in separate single-room wards without contact to surgeons or nurses. If the fever was lower than $37.3^{\circ} \mathrm{C}$ or other symptoms associated with pneumonia were absent after 3 days of admission, surgical procedures would then be performed. The waiting time before surgery was, therefore, longer. During the pandemic, routine surgical techniques should be based on the principles of safety and efficiency, with the main purpose of reducing the incidences of postoperative complications while accelerating the patient's recovery and discharge [13-15]. It was necessary to avoid performing surgical procedures beyond 
Table 4 Postoperative clinicopathological data of all patients enrolled

\begin{tabular}{|c|c|c|c|}
\hline Clinicopathologic data & $\begin{array}{l}\text { PCG }(N=68) \\
M(I Q R) \text { orN } \\
(\%)\end{array}$ & $\begin{array}{l}\text { CG }(N=41) \\
M(I Q R) \text { orN } \\
(\%)\end{array}$ & $P$ \\
\hline Pathological TNM staging & & & 0.394 \\
\hline । & 18 & 8 & \\
\hline$\|$ & 18 & 10 & \\
\hline III & 29 & 23 & \\
\hline IV & 3 & 0 & \\
\hline Complications & & & 0.081 \\
\hline Yes & 6 & 0 & \\
\hline No & 62 & 41 & \\
\hline Postoperative fever & & & 0.379 \\
\hline Yes & 29 & 14 & \\
\hline No & 39 & 27 & \\
\hline Highest temperature $\left({ }^{\circ} \mathrm{C}\right)$ & & & 0.587 \\
\hline$<37.3$ & 39 & 27 & \\
\hline $37.3-38.5$ & 22 & 12 & \\
\hline$>38.5$ & 7 & 2 & \\
\hline Screening examination & & & $0.012^{*}$ \\
\hline None & 16 & 2 & \\
\hline $\mathrm{BRE}+\mathrm{CRP}$ & 8 & 4 & \\
\hline $\mathrm{BRE}+\mathrm{CRP}+\mathrm{CT}$ & 4 & 5 & \\
\hline Nucleic acid test & 0 & 2 & \\
\hline Reason of fever & & & 0.423 \\
\hline Abdominal infection & 1 & 0 & \\
\hline Pulmonary infection & 1 & 0 & \\
\hline Incision infection & 4 & 0 & \\
\hline Anastomotic leakage & 1 & 0 & \\
\hline Unclear & 17 & 11 & \\
\hline None & 5 & 3 & \\
\hline Transfusion of blood & & & 0.422 \\
\hline Yes & 3 & 4 & \\
\hline No & 65 & 37 & \\
\hline $\begin{array}{l}\text { Postoperative hospital stay } \\
\text { (day) }\end{array}$ & $7(6-8)$ & $9(7-11)$ & $0.000^{*}$ \\
\hline Total hospital stay (day) & $11(9-13)$ & $15(13-19)$ & $0.000^{*}$ \\
\hline
\end{tabular}

the established guidelines, including oversized lymph node dissections with uncertain effects and complex digestive tract reconstruction methods. For better surgical outcomes, attention should be paid during surgery to reduce the risk of bleeding. This decreases the chances for blood transfusion.
Table 5 Health economics data of all patients enrolled

\begin{tabular}{llll}
\hline $\begin{array}{l}\text { Health economics data } \\
\text { (10,000 RMB) }\end{array}$ & $\begin{array}{l}\text { PCG }(\boldsymbol{N}=\mathbf{6 8}) \\
\mathbf{M}(\mathbf{I Q R})\end{array}$ & $\begin{array}{l}\text { CG }(\boldsymbol{N}=\mathbf{4 1}) \\
\mathbf{M}(\mathbf{I Q R})\end{array}$ & $\boldsymbol{P}$ \\
\hline Medicine & $2.51(1.79-3.27)$ & $2.89(2.29-4.30)$ & $0.002^{*}$ \\
Examination & $0.05(0.03-0.09)$ & $0.06(0.05-0.08)$ & 0.051 \\
Laboratory test & $0.83(0.68-1.06)$ & $1.00(0.76-1.18)$ & 0.078 \\
Treatment & $7.99(6.59-9.66)$ & $9.00(7.59-11.09)$ & $0.024^{*}$ \\
Surgery & $0.46(0.45-0.47)$ & $0.47(0.40-0.47)$ & 0.527 \\
Anesthesia & $0.20(0.18-0.23)$ & $0.22(0.19-0.23)$ & 0.131 \\
Consumables & $3.94(3.55-4.50)$ & $4.45(3.45-5.45)$ & 0.140 \\
Others & $0.26(0.21-0.34)$ & $0.47(0.36-0.54)$ & $0.000^{*}$ \\
Total costs & $9.23(7.82-10.97)$ & $10.42(8.99-12.57)$ & $0.006^{*}$ \\
\hline PCG Pre-COVD-19 & $C G$ COVD-19 group, M &
\end{tabular}

PCG Pre-COVID-19 group, CG COVID-19 group, M Median, IQR

Inter-quartile range

${ }^{*} P<0.05$, statistically different

During COVID-19 period, more laparoscopic surgeries were performed. COVID-19 is mainly transmitted through respiratory droplets, but the risk of COVID-19 transmission is greatly increased during aerosol generation procedure (AGP) in laparoscopic surgery [16]. Compared with open surgery, there are concerns that the leaked $\mathrm{CO}_{2}$ and smoke may lead to the generation of COVID-19 contaminated aerosols, which may be due to the application of ultrasonic surgical instruments, low gas motility of pneumoperitoneum, and gas expulsion through trocars or ports [17]. Therefore, The Intercollegiate General Surgery Guidance on COVID-19 and The Society of Gastrointestinal and Endoscopic Surgeons (SAGES) initially highlighted the risk of aerosolization during laparoscopic surgery, although their updated guidance acknowledged a lack of evidence $[18,19]$.

However, both open surgery and laparoscopy could generate surgical smoke. When necessary preventive measures are taken, smoke control can be achieved in the closed cavity of laparoscopic surgery, while it cannot be properly controlled in open surgery. The key factors for safe control of smoke hazards are smoke evacuation completely purified by filters and intelligent use of ultrasonic surgical instruments.

We have rigorously analyzed the researches associated with surgical smoke and found there was lacking of enough evidence that laparoscopic surgery is routinely prohibited simply due to the aerosol generation procedure during operation. Moreover, there was less evidence that had shown relationship between COVID-19 transmission and surgical smoke generated by ultrasonic surgical instruments [20-23]. By the way, during the COVID-19 pandemic, we also use the smoke extractor with vacuum motors which were applied to inhale smoke from the surgical site through a completely enclosed vacuum tube and filter. Medical staffs were therefore protected from potential contamination. 
Therefore, we have used laparoscopy more frequently during COVID-19, and information about laparoscopic surgeries, such as surgery time, blood loss and complications, indicated that the method was safe and feasible. However, although we have not found any evidence of particular risk in laparoscopic surgery, the risk might still exist. Further investigation in this field is of critical importance.

The hospitalization costs were significantly increased in CG. As for the reason, we would like to elaborate on prolonged hospital stay. Patients in CG were observed in the separate single-room wards for 3 days to prevent potential infection. Therefore, the preoperative hospital stay was longer. As for the post-operative hospital stay, during the COVID-19 period, patients had to have their stitches removed in outpatient clinics and local hospitals after discharge. This increased the risk of unnecessary viral infections. It was better to stay longer in our department until stitches were removed. The hospital stay period after surgery was, therefore, longer in CG.

We found no statistically differences in postoperative fever. If the patient developed fever of unknown cause after surgery, appropriate ward isolation measures should be taken and measurements of postoperative blood routine, C-reactive protein, procalcitonin, chest $\mathrm{CT}$, and new coronavirus nucleic acid tests were necessary.

\section{Limitations}

This study had some limitations. Firstly, the presented results are for a short-term follow-up period which fails to illustrate the long-term outcomes such as progression-free survival and mortality. Secondly, oversized lymph node dissections with uncertain effects were not performed beyond authoritative guidelines, which may have also impact on oncologic outcome. More studies are needed to investigate the impact of these procedures on oncologic outcomes. Thirdly, the study was retrospectively performed in a single center and may therefore involve selection bias.

\section{Conclusions}

In conclusion, there are no studies on the impact of COVID-19 on gastric cancer patients. The full impact of COVID-19 on surgical procedures is still unknown. As this pandemic has affected global economics, politics, hospital management, health strategies and personnel, its impact may only become evident in the long term. This study provides an opportunity for surgical residents to reflect on their own service and any contingency plans they have to tackle this crisis.

\section{Abbreviations}

COVID-19: Coronavirus disease 2019; PCG: Pre-COVID-19 group; CG: COVID-19 group; IQR: Interquartile range; WHO: World Health Organization; NCAT: Neoadjuvant chemotherapy; NCCN: National Comprehensive Cancer
Network; AGP: Aerosol generation procedure; SAGES: Society of Gastrointestinal and Endoscopic Surgeons

\section{Acknowledgements}

Not applicable.

\section{Authors' contributions}

XHD and SYX conceived the analysis. YXL, CZH and YCL extracted all data. YFW,PYZ and $X L X$ undertook and refined the inclusion process. YXL, CZH and YCLCo-wrote the paper. YXL, YCL and YFW undertook the statistical analyses. All authors contributed to and revised the final manuscript. The author(s) read and approved the final manuscript.

\section{Funding}

This work was supported by grants from the National Natural Science Foundation of China (No. 81871317).

\section{Availability of data and materials}

The datasets used and/or analysed during the current study are available from the corresponding author on reasonable request.

Ethics approval and consent to participate

This study was approved by the Institutional Review Board of General Hospital of PLA(S2020-003-01)

\section{Consent for publication}

Not applicable.

\section{Competing interests}

The authors declared no competing interests.

\section{Author details}

${ }^{1}$ Department of General Surgery, Chinese PLA General Hospital, Beijing 100853, PR China. ${ }^{2}$ Department of Hospitalization management, Chinese PLA General Hospital, Beijing 100853, PR China.

Received: 12 June 2020 Accepted: 27 September 2020

Published online: 02 October 2020

\section{References}

1. Lu H, Stratton CW, Tang YW. Outbreak of pneumonia of unknown etiology in Wuhan, China: the mystery and the miracle. J Med Virol. 2020;92(4):401-2.

2. Rothan HA, Byrareddy SN. The epidemiology and pathogenesis of coronavirus disease (COVID-19) outbreak. J Autoimmun. 2020;109:102433.

3. Remuzzi A, Remuzzi G. COVID-19 and Italy: what next? Lancet. 2020; 395(10231):1225-8.

4. Wang D, Hu B, Hu C, Zhu F, Liu X, Zhang J, Wang B, Xiang H, Cheng Z, Xiong Y, et al. Clinical characteristics of 138 hospitalized patients with 2019 novel coronavirus-infected pneumonia in Wuhan, China. JAMA. 2020; 323(11):1061-9

5. Danese S, Cecconi M, Spinelli A. Management of IBD during the COVID-19 outbreak: resetting clinical priorities. Nat Rev Gastroenterol Hepatol. 2020; 17(5):253-5.

6. Gagliano A, Villani PG, Co' FM, et al. COVID-19 Epidemic in the Middle Province of Northern Italy: Impact, Logistics, and Strategy in the First Line Hospital [published online ahead of print, 2020 Mar 24]. Disaster Med Public Health Prep. 2020;1-5. https://doi.org/10.1017/dmp.2020.51.

7. Gu J, Han B, Wang J. COVID-19: gastrointestinal manifestations and potential fecal-oral transmission. Gastroenterology. 2020;158(6):1518-9.

8. Tan YM, Chow PK, Tan BH, Kurup A, Tan BK, Tan FL, Seldrup J, Heng DM, Ang B, Green J, et al. Management of inpatients exposed to an outbreak of severe acute respiratory syndrome (SARS). J Hosp Infect. 2004;58(3):210-5.

9. Pellino G, Spinelli A. How COVID-19 outbreak is impacting colorectal Cancer patients in Italy: a long shadow beyond infection. Dis Colon Rectum. 2020; 63(6):720-2

10. Wang $\mathrm{H}$, Zhang L. Risk of COVID-19 for patients with cancer. Lancet Oncol. 2020;21(4):e180.

11. Tolone S, Gambardella C, Brusciano L, del Genio G, Lucido FS, Docimo L. Telephonic triage before surgical ward admission and telemedicine during COVID-19 outbreak in Italy. Effective and easy procedures to reduce inhospital positivity. Int J Surg. 2020;78:123-5. 
12. Gambardella C, Pagliuca R, Pomilla G, Gambardella A. COVID-19 risk contagion: organization and procedures in a South Italy geriatric oncology ward. J Geriatr Oncol. 2020;11(7):1187-8.

13. Chen YH, Peng JS. Treatment strategy for gastrointestinal tumor under the outbreak of novel coronavirus pneumonia in China. Zhonghua Wei Chang Wai Ke Za Zhi. 2020;23(2):I-IV.

14. Hu XH, Niu WB, Zhang JF, Li BK, Yu B, Zhang ZY, Zhou CX, Zhang XN, Gao Y, Wang GY. Treatment strategies for colorectal cancer patients in tumor hospitals under the background of corona virus disease 2019. Zhonghua Wei Chang Wai Ke Za Zhi. 2020;23(3):201-8.

15. Ma FH, Hu HT, Tian YT. Surgical treatment strategy for digestive system malignancies during the outbreak of novel coronavirus pneumonia. Zhonghua Zhong Liu Za Zhi. 2020;42(0):E001.

16. Howard BE. High-risk aerosol-generating procedures in COVID-19: respiratory protective equipment considerations. Otolaryngol Head Neck Surg. 2020;163(1):98-103.

17. Zheng $\mathrm{MH}$, Boni $\mathrm{L}$, Fingerhut $\mathrm{A}$. Minimally invasive surgery and the novel coronavirus outbreak: lessons learned in China and Italy. Ann Surg. 2020; 272(1):e5-6.

18. Moletta L, Pierobon ES, Capovilla G, Costantini M, Salvador R, Merigliano S, Valmasoni M. International guidelines and recommendations for surgery during Covid-19 pandemic: a systematic review. Int J Surg. 2020;79:180-8.

19. Vigneswaran Y, Prachand VN, Posner MC, Matthews JB, Hussain M. What is the appropriate use of laparoscopy over open procedures in the current COVID-19 climate? J Gastrointest Surg. 2020;24(7):1686-91.

20. Mintz Y, Arezzo A, Boni L, Baldari L, Cassinotti E, Brodie R, Uranues S, Zheng M, Fingerhut A. The risk of COVID-19 transmission by laparoscopic smoke may be lower than for laparotomy: a narrative review. Surg Endosc. 2020; 34(8):3298-305.

21. Morris SN, Fader AN, Milad MP, Dionisi HJ. Understanding the "scope" of the problem: why laparoscopy is considered safe during the COVID-19 pandemic. J Minim Invasive Gynecol. 2020;27(4):789-91.

22. Tuech JJ, Gangloff A, Di Fiore F, Michel P, Brigand C, Slim K, Pocard M Schwarz L. Strategy for the practice of digestive and oncological surgery during the Covid-19 epidemic. J Visc Surg. 2020;157(3S1):S7-S12.

23. Veziant J, Bourdel N, Slim K. Risks of viral contamination in healthcare professionals during laparoscopy in the Covid-19 pandemic. J Visc Surg. 2020;157(3S1):S59-62.

\section{Publisher's Note}

Springer Nature remains neutral with regard to jurisdictional claims in published maps and institutional affiliations.

Ready to submit your research? Choose BMC and benefit from:

- fast, convenient online submission

- thorough peer review by experienced researchers in your field

- rapid publication on acceptance

- support for research data, including large and complex data types

- gold Open Access which fosters wider collaboration and increased citations

- maximum visibility for your research: over $100 \mathrm{M}$ website views per year

At $\mathrm{BMC}$, research is always in progress.

Learn more biomedcentral.com/submissions 